\title{
Batarya Tipi Kafeslerde Işığın Geliş Açısının Yumurta Verimi ve Kalitesi Üzerine Etkisi

\author{
İsmail Türker ${ }^{1}$ (D), Serdar Kamanlı² (D), Mehmet Fatih Çelen ${ }^{3}$
} \\ ${ }^{1}$ Uşak Üniversitesi, Ziraat Fakültesi, Zootekni Bölümü, Uşak \\ ${ }^{2}$ Tavukçuluk Araştırma Enstitüsü, Ankara \\ ${ }^{3}$ Uşak Üniversitesi, Ziraat Fakültesi, Zootekni Bölümü, Uşak
}

Geliş Tarihi / Received Date: 03.10.2021

Kabul Tarihi / Accepted Date: 18.10.2021

\section{Özet}

Araştırma yumurta tavuğu kafes sistemlerinde ışığın geliş açısının tavukların bazı verim özellikleri üzerine etkisini belirlemek üzere yürütülmüştür. Her bir kafes katında tavuk göz seviyesinde ışığın geliş açısı $105^{\circ}, 110^{\circ}$ ve $120^{\circ}$ olacak şekilde üç deneme grubu oluşturulmuştur. Araştırmada üç katlı batarya tip bireysel kafes sistemi bulunan bir kümeste, her grupta bireysel olarak barındırılan 30 tavuk olmak üzere 52 haftalık yaşta 90 adet Atak-S ticari kahverengi yumurtacı tavuğu kullanılmıştır. Araştırma tesadüf parselleri deneme desenine uygun olarak 30 tekerrür ile yürütülmüştür. Tavukların 5 haftalık verim süresince yumurta verimi, yumurta ağırlığı, şekil indeksi, kabuk kalınlığı, kabuk kırılma direnci, ak yüksekliği, sarı yüksekliği ve haugh birimi özellikleri tespit edilmiştir. Araştırmada elde edilen verilerin değerlendirilmesi neticesinde yumurta verimi ve sarı yüksekliği özellikleri üzerine ışığın geliş açısının önemli bir etkiye sahip olduğu $(P<0,05)$, yumurta ağırlığı, şekil indeksi, kabuk kalınlığı, kabuk kırılma direnci, ak yüksekliği ve haugh birimi özellikleri üzerine etkisinin bulunmadığı tespit edilmiştir $(P>0,05)$. Sonuç olarak, ışı̆̆ın geliş açısının yüksek olması ile sarı yüksekliğinin düştüğü belirlenmiş, fakat yumurta verimi ile ışık geliş açısının doğrusal olarak ilişkilendirilemeyeceği kanaatine varılmıştır.

Anahtar Kelimeler: ışık, açı, yumurta verimi, yumurta kalitesi, kafes

\section{The Effect of Light Incidence Angle on Egg Production and Quality in Battery Type Cages}

\begin{abstract}
The research was carried out to determine the effect of the light incidence angle on some characteristics of hens in laying cage systems. In each cage, 3 groups of 1050, 1100 and 1200 were formed according to the light incidence angle at the chicken eye level. In the study, total of 90 Atak-S commercial brown layer hens at 52 weeks of age (30 hens in each group) were used individually in a three-floor battery type individual cage system. The research was carried out in a completely randomized design with 30 replications. Egg production, egg weight, shape index, shell thickness, shell break strength, white height, yolk height and haugh unit characteristics were determined during the 5-week of laying period. As a result of the evaluation of the data obtained in the research, it was determined that the light incidence angle had a significant effect on egg production and egg yolk height $(P<0.05)$. However, there was no significant effect on egg weight, shape index, shell thickness, shell break strength, white height and haugh unit characteristics ( $P>0.05)$. As a result, it was concluded that the height of the yolk decreased with the high angle of light incidence, and the egg production and light incidence angle could not be correlated linearly.
\end{abstract}

Keywords: light, angle, egg production, egg quality, cage 


\section{Giriş}

Işığın başta tavuklar olmak üzere tüm kanatlı hayvanlarda ortaya çıkardığı etkileri inceleyen araştırmalar 19. yüzyılda Amerikalı fizikçi Waldorf'un öncülüğünde başlamış olup, günümüzde hala sürmektedir. Kanatlı hayvanlarda çevreden gelen ışık pineal ve retinal reseptörlerle alınıp beyindeki hipotalamusu etkiler. Buradan salgılanan hormon uyarıcı faktörleri, hipofizin anterior lobunu aktive ederek, folikül uyarıcı hormonun (FSH) salgılanmasını sağlar. FSH yumurtalıktaki folikülleri geliştirir ve buradan salgılanan östrojen hormonunu kontrol eder. Foliküller tam olgunlaşınca hipofizden LH hormonu salgılanır. Olgunlaşmış folikül ovulasyona uğrayarak infundibuluma düşer. Boşalan folikülden salgılanan progesteron hormonu hipofiz bezini etkileyerek daha fazla LH salınımını engeller. Böylece yumurta kanalındaki bir yumurta yumurtlanmadan yeni bir ovulasyon olması engellenir (Durmuş vd., 2004).

Işığın yumurtlama periyodunda olduğu kadar yumurtlama öncesi dönemde de önemli fizyolojik etkilere sahip olduğu (Christmas vd., 1996); Leeson ve Lewis'e (2004) atfen Yıldırım vd. (2008) tarafından bildirilmiştir. Işık şiddetinin tavukların fizyolojik intiyaçlarını karşılamadan daha ziyade tavukların yeterince denetimi ve onlar için uygun bir ortam sağlamak için seçilmesinin uygun olduğu bildirilmiştir (Morris, 1994). Darre ve Rock (1995) tavukların fizyolojik ışık ihtiyacının yaklaşık olarak 3 lüks, Levis vd. (1999) ise tavukların fotoperiyodik mekanizmanın beyaz ışıkla uyarılması için ışık şiddetinin 0,9-1,7 lüks arasında olmasının yeterli olacağını belirtmişlerdir. Bununla birlikte tavuklarda ışık şiddetinin yanında ışık rengi, kaynağı, düzgün olarak dağııımı ve uygulanan aydınlatma programları da verim üzerinde etkili olmaktadır.

Yumurta tavukçuluğu büyük oranda kafes sistemli kümeslerde yapılmaktadır. Her ne kadar tüm kafes katlarında aydınlatma, havalandırma ve ısıtma gibi tüm çevre faktörleri homojen olarak kümes içerisinde sağlamaya çalışılsa da kafes katı sayısının artmasıyla bu durumun zor olduğu bilinmektedir. Konuyla ilgili olarak yapılan değişik araştırmalarda kafes katları ve kafes konumları arasında bazı verim özellikleri arasında önemli farlılık bulunduğu bildirilmiştir (Bougon vd., 1986; Hemsworth ve Barnett, 1989; Jackson ve Waldroup,1987; Kılıç ve Şimşek, 2006; Vits vd., 2006; Yetişir ve Sarıca, 2004).

Aydınlatma programları ve ışığın tavuklar üzerinde etkisi üzerinde araştırmalar devam etmektedir. Gelişen teknolojilerle birlikte tavuklarda uygun aydınlatma programları ve ışık kaynağı konumunun belirlenmesi üzerine araştırmalar sürmektedir. Bu çalışmanın amacı ışığın tavukların göz hizasına geliş açısının yumurta verimi ve bazı kalite özellikleri üzerine etkisinin belirlenmesi amaçlanmıştır.

\section{Materyal ve Yöntem}

Araştırmada 52 haftalık yaştaki 90 adet ATAK-S kahverengi yumurtacı tavukları kullanıımıştır. Tavukların beslenmesinde Tablo 1' de besin madde kompozisyonu verilen, (0-3 hafta yumurta civciv yemi, 4-10. hafta piliç büyütme yemi, 11-16. hafta piliç geliştirme yemi, 17-40. hafta yumurta tavuğu 1. dönem yemi ve 41-57 hafta yumurta tavuğu 2. dönem yemi) yemi kullanılmıştır.

Araştırma, tesadüf parselleri deneme desenine uygun şekilde, batarya tip 3 katlı taban alanı $1200 \mathrm{~cm}^{2}$ olan bireysel kafeslerde ve 30 tekerrürlü olarak 5 hafta süreyle yürütülmüştür. Her kafes katı grup olarak ve kafeslere bireysel olarak yerleştirilen her bir tavuk tekerrür olarak ele alınmıştır. Kafes katlarına hayvanın göz seviyesi ve ışık kaynağı arasındaki açı ve ışık şiddeti lüksmetre ile ölçülerek aşağıda belirtilen deneme grupları oluşturulmuştur. Gruplarda ışık şiddetinin dağılım grafiği Şekil 1'de verilmiştir. 


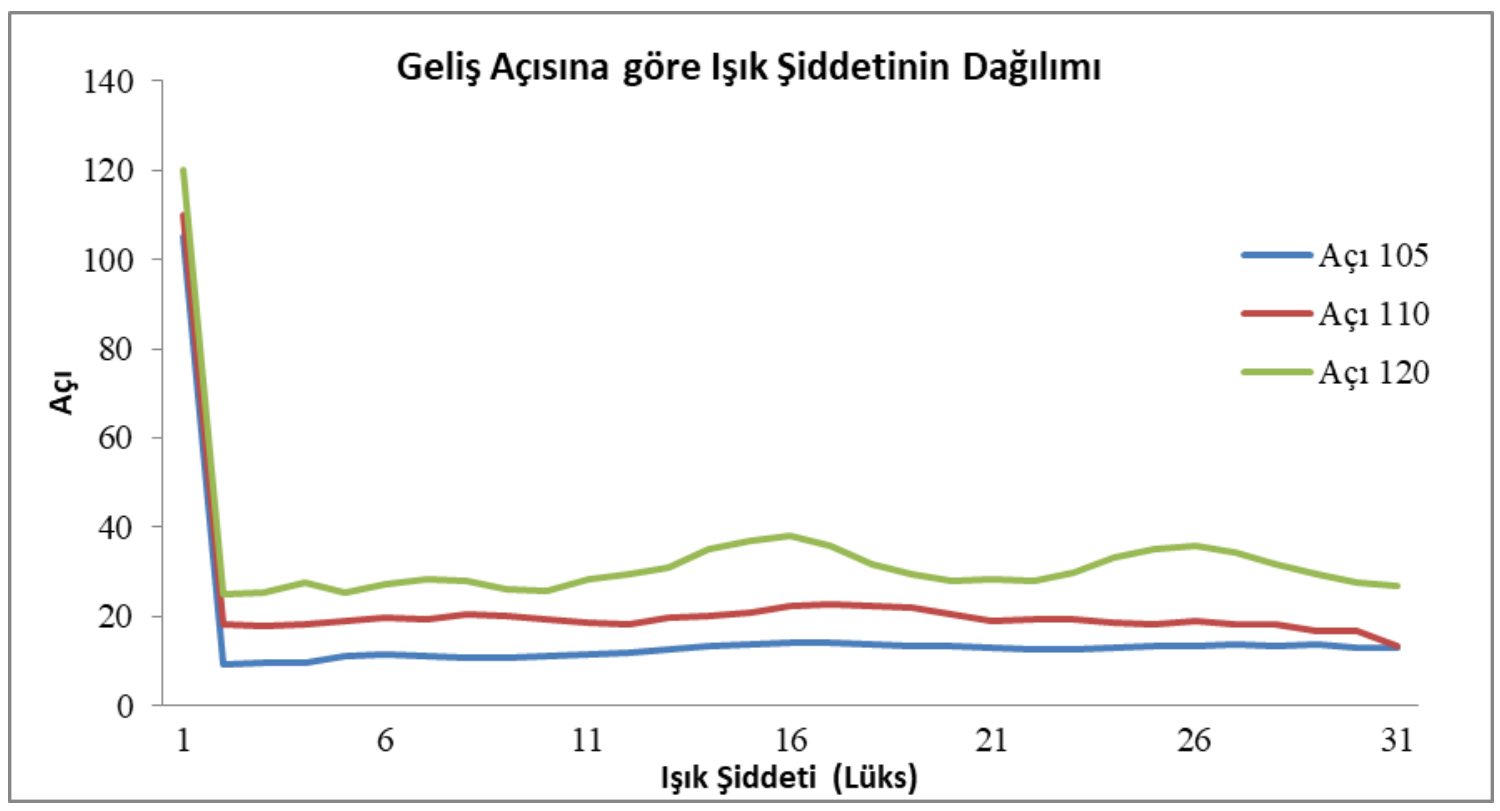

Şekil 1. Geliş Açısına Göre Işık Şiddetinin Dağılımı

1. grup: Işık geliş açısı $105^{\circ}$ kafes birinci katı (ışık şiddeti $\square, 9$ lüks)

2. grup: Işık geliş açısı $110^{\circ}$ kafes ikinci katı (ışık şiddeti $\square$ 14,0 lüks)

3. grup: Işık geliş açısı $120^{\circ}$ kafes üçüncü katı (ışık şiddeti $\square 4,7$ lüks)

Araştırma süresince aşağıda belirtilen verim ve yumurta kalite özellikleri tespit edilmiştir. Her gruptan aynı gün toplanan yumurtalar oda sıcaklığında ve \%75 nemli ortamda 24 saat bekletildikten sonra yumurta kalite özellikleri belirlenmiştir.

Yumurta verimi (adet): Her bir grupta bireysel kafeslerde bulunan 30'ar adet tavuğun verimleri belirlenerek adet yumurta verimi olarak hesaplanmıştır.

Yumurta ağırlığı (g): Her bir grupta bulunan tavuklardan elde edilen yumurtalar toplanmış ve 0,01 gram hassasiyetindeki terazi ile belirlenmiştir.

Şekil İndeksi: Yumurtanın en ve boy uzunlukları kumpas yardımıyla ölçülerek (en/boy) *100 formülü ile hesaplanmıştır.

Kabuk Kırılma Direnci (N): Kabuk kırılma direnci ölçüm aleti yardımıyla (Newton/cm²) olarak belirlenmiştir.

Kabuk Kalınlığı (mm): Mikrometre yardımıyla mm olarak belirlenmiştir.

Sarı Yüksekliği (mm): Üçayaklı mikrometre yardımıyla mm olarak tespit edilmiştir.

Ak Yüksekliği (mm): Üçayaklı mikrometre yardımıyla mm olarak tespit edilmiştir.

Haugh Birimi: Yumurta ağırlığı ve ak yüksekliğinden yararlanılarak aşağıdaki formül ile hesaplanmıştır: Haugh birimi=100 Log $\left(\mathrm{H}+7,57-1,7 \mathrm{G}^{0.37}\right)$

$\mathrm{H}=\mathrm{Ak}$ yüksekliği $(\mathrm{mm})$

$\mathrm{G}=$ Yumurta ağırlığı (g)

İstatistik Analiz: Araştırmada elde edilen verilerin dağılım kontrolü Kolmogorov-Simirnov testi ile yapılmıştır. Varsayımları yerine getiren özelliklerin değerlendirilmesinde tekyönlü varyans analizi (one-way ANOVA), aralarında farlılık bulunan grupların belirlenmesinde Tukey çoklu karşılaştırma testi kullanılmıştır. 
Tablo 1. Yem Materyali Besin Madde Kompozisyonu

\begin{tabular}{|c|c|c|c|c|c|}
\hline $\begin{array}{l}\text { Temel besin } \\
\text { maddeleri }\end{array}$ & $\begin{array}{l}0-3 \text { hafta } \\
\text { civciv yemi }\end{array}$ & $\begin{array}{c}4-10 \text { hafta } \\
\text { piliç büyütme } \\
\text { yemi }\end{array}$ & $\begin{array}{c}11-16 \text { hafta } \\
\text { piliç gelişstirme } \\
\text { yemi }\end{array}$ & $\begin{array}{c}17-40 \text { hafta } \\
\text { yumurta } \\
\text { tavuğu } 1 . \\
\text { dönem yemi }\end{array}$ & $\begin{array}{c}41-58 \text { hafta } \\
\text { yumurta } \\
\text { tavuğu } 2 . \\
\text { dönem yemi }\end{array}$ \\
\hline $\begin{array}{l}\text { Kuru madde, } \\
\text { en az (\%) }\end{array}$ & 88 & 88 & 88 & 88 & 88 \\
\hline $\begin{array}{l}\text { Ham kül, en } \\
\text { çok (\%) }\end{array}$ & 8 & 8 & 8 & 8 & 8 \\
\hline $\begin{array}{l}\text { Ham protein, } \\
\text { en az (\%) }\end{array}$ & 19 & 18 & 16 & 18 & 17 \\
\hline $\begin{array}{l}\text { Metabolik } \\
\text { enerji, en az } \\
\text { (kcal/kg) }\end{array}$ & 2900 & 2800 & 2700 & 2800 & 2700 \\
\hline $\begin{array}{l}\text { Kalsiyum, en } \\
\text { az-en çok (\%) } \\
\text { Yararlanılabilir }\end{array}$ & $1-1,2$ & $1-1,1$ & $0,9-1$ & $3,5-4$ & $3,8-4,2$ \\
\hline $\begin{array}{l}\text { fosfor en az } \\
\text { (\%) }\end{array}$ & 0,45 & 0,42 & 0,40 & 0,40 & 0,37 \\
\hline Lisin, en az (\%) & 1,15 & 0,98 & 0,72 & 0,75 & 0,75 \\
\hline $\begin{array}{l}\text { Metionin, en } \\
\text { az (\%) }\end{array}$ & 0,55 & 0,47 & 0,35 & 0,47 & 0,42 \\
\hline $\begin{array}{l}\text { Metionin+sisti } \\
\text { n, en az (\%) }\end{array}$ & 0,85 & 0,76 & 0,58 & 0,78 & 0,72 \\
\hline $\begin{array}{l}\text { Triptofan, en } \\
\text { az (\%) }\end{array}$ & 0,20 & 0,19 & 0,17 & 0,20 & 0,19 \\
\hline $\begin{array}{l}\text { Tuz, en az-en } \\
\text { çok (\%) }\end{array}$ & $0,35-0,50$ & $0,35-0,50$ & $0,35-0,50$ & $0,35-0,50$ & $0,35-0,50$ \\
\hline $\begin{array}{l}\text { Ham selüloz, } \\
\text { en çok (\%) }\end{array}$ & 4,5 & 5 & 6 & 6 & 6 \\
\hline $\begin{array}{l}\text { Linoleik asit, } \\
\text { en az (\%) }\end{array}$ & 1,5 & 1,25 & 1,0 & 1,7 & 1,5 \\
\hline $\begin{array}{l}\text { A vitamini } \\
(\mathrm{IU} / \mathrm{kg})\end{array}$ & 13000 & 13000 & 10000 & 12000 & 12000 \\
\hline $\begin{array}{l}D_{3} \text { vitamini } \\
(\mathrm{IU} / \mathrm{kg})\end{array}$ & 3000 & 3000 & 2000 & 2500 & 2500 \\
\hline $\begin{array}{l}\text { E vitamini } \\
(\mathrm{mg} / \mathrm{kg})\end{array}$ & 20 & 20 & 20 & 20 & 20 \\
\hline $\begin{array}{l}\mathrm{K}_{3} \text { vitamini } \\
(\mathrm{mg} / \mathrm{kg})\end{array}$ & 2 & 2 & 2 & 2 & 2 \\
\hline $\begin{array}{l}B_{2} \text { vitamini } \\
(\mathrm{mg} / \mathrm{kg})\end{array}$ & 5 & 5 & 5 & 5 & 5 \\
\hline $\begin{array}{l}\text { B }_{12} \text { vitamini } \\
(\mathrm{mg} / \mathrm{kg})\end{array}$ & 0,02 & 0,02 & 0,01 & 0,01 & 0,01 \\
\hline Niasin $(\mathrm{mg} / \mathrm{kg})$ & 60 & 60 & 30 & 25 & 25 \\
\hline $\begin{array}{l}\text { Mangan } \\
(\mathrm{mg} / \mathrm{kg})\end{array}$ & 100 & 100 & 100 & 60 & 60 \\
\hline Çinko (mg/kg) & 70 & 70 & 70 & 40 & 40 \\
\hline Demir (mg/kg) & 40 & 40 & 40 & 40 & 40 \\
\hline Bakır (mg/kg) & 7 & 7 & 7 & 7 & 7 \\
\hline $\begin{array}{l}\text { Selenyum } \\
\text { (mg/kg) }\end{array}$ & 0,2 & 0,2 & 0,2 & 0,2 & 0,2 \\
\hline Kobalt (mg/kg) & 0,5 & 0,5 & 0,5 & 0,5 & 0,5 \\
\hline
\end{tabular}




\section{Bulgular ve Tartışma}

Araştırma verilerinin değerlendirilmesi neticesinde elde edilen sonuçlar Tablo 2'de verilmiştir. Araştırmada üzerinde durulan özelliklerden yumurta verimi ve sarı yüksekliği bakımından gruplar arasında önemli farklılık olduğu tespit edilmiştir $(P<0,05)$. Yumurta şekil indeksi, ağırlığı, kabuk kalınlığı, kabuk kırılma direnci, ak yüksekliği ve haugh birimi bakımından gruplar arasında önemli bir farklılık bulunmadığı belirlenmiştir $(P>0,05)$.

Tablo 2. Yumurta verimi ve kalitesine ait araştırma bulguları

\begin{tabular}{|c|c|c|c|c|c|c|c|c|}
\hline Gruplar & $\begin{array}{l}\text { Yumurta } \\
\text { verimi } \\
\text { (adet) }\end{array}$ & $\begin{array}{l}\text { Şekil } \\
\text { indeksi }\end{array}$ & $\begin{array}{l}\text { Yumurt } \\
\text { a } \\
\text { ağırlığı } \\
\text { (g) }\end{array}$ & $\begin{array}{l}\text { Kabuk } \\
\text { kalınlığı } \\
(\mathrm{mm})\end{array}$ & $\begin{array}{l}\text { Kabuk } \\
\text { kırılma } \\
\text { direnci } \\
\text { (N) }\end{array}$ & $\begin{array}{l}\text { Ak } \\
\text { yüksekliği } \\
(\mathrm{mm})\end{array}$ & $\begin{array}{l}\text { Sarı } \\
\text { yüksekliği } \\
(\mathrm{mm})\end{array}$ & $\begin{array}{l}\text { Haugh } \\
\text { birimi }\end{array}$ \\
\hline $\begin{array}{l}1 \text { grup } \\
\text { (Işık açısı } \\
105^{0} \text { ) }\end{array}$ & $\begin{array}{l}29,00 \pm 0,8 \\
4^{\mathrm{ab}}\end{array}$ & $75,33 \pm 0,36$ & $\begin{array}{l}64,23 \pm 1 \\
, 34\end{array}$ & $\begin{array}{l}0,32 \pm 0,00 \\
5\end{array}$ & $\begin{array}{l}35,26 \pm 1,9 \\
7\end{array}$ & $7,92 \pm 0,39$ & $\begin{array}{l}11,94 \pm 0,0 \\
8^{a}\end{array}$ & $\begin{array}{l}87,32 \pm 2,1 \\
2\end{array}$ \\
\hline $\begin{array}{l}\text { 2. grup } \\
\text { (Işık açısı } \\
\left.110^{\circ}\right)\end{array}$ & $\begin{array}{l}27,20 \pm 0,7 \\
2^{b}\end{array}$ & $\begin{array}{l}75,105 \pm 0,5 \\
4\end{array}$ & $\begin{array}{l}63,45 \pm 1 \\
, 20\end{array}$ & $\begin{array}{l}0,33 \pm 0,00 \\
6\end{array}$ & $\begin{array}{l}32,11 \pm 1,9 \\
7\end{array}$ & $7,55 \pm 0,26$ & $\begin{array}{l}11,96 \pm 0,1 \\
0^{a}\end{array}$ & $\begin{array}{l}86,50 \pm 1,8 \\
6\end{array}$ \\
\hline $\begin{array}{l}\text { 3. grup } \\
\text { (Işık açısı } \\
\left.120^{\circ}\right)\end{array}$ & $\begin{array}{l}29,73 \pm 0,3 \\
5^{a}\end{array}$ & $\begin{array}{l}75,588 \pm 0,4 \\
9\end{array}$ & $\begin{array}{l}66,44 \pm 1 \\
, 34\end{array}$ & $\begin{array}{l}0,32 \pm 0,00 \\
6\end{array}$ & $\begin{array}{l}29,74 \pm 2,0 \\
1\end{array}$ & $7,89 \pm 0,30$ & $\begin{array}{l}11,56 \pm 0,1 \\
2^{b}\end{array}$ & $\begin{array}{l}86,69 \pm 1,9 \\
1\end{array}$ \\
\hline
\end{tabular}

Yumurta verimi dikkate alındığında 3. grup 2. gruptan daha yüksek yumurta verimine sahip olmuştur. Bir ile üçüncü gruptaki hayvanların yumurta verimleri birbirine benzerlik göstermiştir. Burada dikkati çeken husus ışık geliş açısı farklı olan $\left(105^{\circ}-120^{\circ}\right)$ gruplar arasında yumurta verimlerinin benzerlik gösterip ışık açısı $110^{\circ}$ olan 2. Grupta düşük olmasıdır. Araştırmadan elde edilen bu sonuç ışık geliş açısı ve buna bağlı olarak ışık şiddeti ile yumurta verimi arasında doğrusal bir ilişkinin olmadığını, ortaya çıkan farklılıklara havalandırma gibi başka faktörlerin etkili olabileceğini ortaya koymaktadır. Üç katı kafeslerde ikinci kat orta kısımda yer aldığı için kafesin diğer kısımları kadar havalandırma yapılamamaktadır.

$\mathrm{Bu}$ durum ışık şiddetinin tavukların fizyolojik ihtiyaçlarını karşılamadan daha ziyade tavukların yeterince denetimi ve onlar için uygun bir ortam sağlamak için seçilmesini tavsiye eden Morris (1994), tavukların fizyolojik ışık ihtiyacının yaklaşık olarak 3 lüks olmasını bildiren Darre ve Rock (1995) fotoperiyodik mekanizmanın beyaz ışıkla uyarılması için ışık şiddetinin 0,9-1,7 lüks arasında olmasının yeterli olacağını belirten Levis vd.'nin (1999) bildirimleri ve kafes katları arasında yumurta verimi bakımından farklılık bulunmadığını belirten Durmuş ve Kamanlı'nın (2012) bulguları ile benzerlik göstermektedir. Ancak Yıldırım vd. (2008) kafes katları arasında yumurta verimi bakımından farklılık bulunduğunu belirterek, yüksek ışık şiddeti yüksek olan grubun yumurta verimi bakımından diğerlerinden düşük olduğunu bildirmiştir. Bu durumda ışık şiddetinin düşük olmasından daha ziyade çok yüksek olmasının olumsuz etkileri üzerinde durulmasının gerekli olacağı düşünülmektedir.

Araştırmada üzerinde durulan özelliklerden şekil indeksi, yumurta ağırlığı, kabuk kalınlığı, kabuk kırılma direnci ve haugh birimi gibi özelliklerin ışığın geliş açısı ve buna mukabil ışık şiddetinden etkilenmediği görülmektedir. Yıldırım vd. (2008) kafes katları bakımından yumurta ağırlığı ve şekil indeksi arasında farklılık bulunmadığı yönündeki bulguları ile araştırma bulguları benzerlik göstermektedir. Ancak aynı araştırmacıların yumurta kabuk kırılma direnci ve ak indeksi bakımından daha az ışık şiddetine maruz kalan kafesin alt katlarındaki tavuklardan elde edilen yumurtaların kabuk kırılma direnci ve ak indeksi bakımından daha yüksek değere sahip olduğunu belirten bulguları ile çelişmektedir. Ancak burada söz konusu araştırma 4 katı ıafeslerde yapılmış ve 1 . kattaki ışık şiddeti 68,08 lüks, ikinci katta 41,68 lüks gibi yüksek bir ışık şiddetinin bulunduğunun dikkate alınması gerekmektedir. Araştırmada bu gruplardan elde edilen yumurtaların kabuk kırılma direnci ve ak 
indeksi değerlerinin diğer gruplardan (ışık şiddeti 31,54 ve 22,08 lüks) düşük olduğu görülmektedir. Bu durum yüksek ışık şiddetinin olumsuz bir etkisi olarak değerlendirilebilir.

Araştırmada sarı yüksekliği bakımından gruplar arasında ışık şiddetine bağlı olarak yüksek ışık şiddetine maruz kalan (24,7 lüks) 3.gruptaki tavuklardan elde edelin yumurtaların ak yüksekliği diğer gruplardan daha düşük bulunmuştur. Bunun nedeni olarak yüksek ışık şiddetinin ovulasyonun daha erken olması yönünde etkili olduğunu söylemek mümkündür. Bu tür yumurtalarda ak/sarı oranı ve ağırlığının tespit edilerek ışık etkisinin net olarak ortaya konulmasında fayda bulunmaktadır. Gruplar arasında yumurta ağırlığı ve ak yüksekliği bakımından farklılık oluşmaması haugh birimi bakımından da farklııı oluşmamasına yol açmıştır. Haugh birimi yumurta ağırlığı ve ak yüksekliğinin logaritmik bir ifadesi olduğu için matematiksel olarak da beklenilen sonuç bu yöndedir.

\section{Sonuç ve Öneriler}

Yumurta tavukçuluğu büyük oranda kafes sistem kümeslerde yapılmaktadır. Bu kümeslerde başta ışık ve havalandırma olmak üzere verim üzerinde etki eden faktörler homojen olarak sağlanılamamaktadır. Bunların etkisi ile yumurta üretiminde aynı genotip kullanılsa bile bir örnek yumurta üretim oranı düşmektedir. Işık şiddeti de tavukların verimleri üzerine etkili faktörlerden biridir. Bu nedenle ışık şiddetinin tavukların fizyolojisini olumsuz etkilemeyecek düzeyde tutulması önemlidir. Araştırmalardan elde edilen sonuçlar düşük ışık şiddetinden daha ziyade yüksek olması ile olumsuz etkilerin ortaya çıktığını göstermektedir. Araştırmada ışığın geliş açısının tavukların bazı verim özellikleri üzerine etkili olduğu belirlenmiş olup, ışık şiddeti ve buna etkili olan ışık kaynağıhayvan mesafesi, ışık kaynağı açısı-hayvan konumu, kullanılan lambalar ve kafes katları sayısı gibi faktörlerin etkisinin minimum düzeye indirilerek mümkün olduğunca homojen ışık şiddeti sağlanacak kafes sistemlerinin geliştirilmesinin uygun olacağı düşünülmektedir.

\section{Yazar Katkısı}

Ismail Türker, deneysel ortamını hazırlandı ve deneysel süreci takip etti. Serdar Kamanlı, verilerin toplanması işlemini gerçekleştirdi. Mehmet Fatih Çelen, istatistik analizleri yaptı. Yazarlar makaleyi birlikte yazdı, okudu ve onayladı.

\section{Etik}

Bu makalenin yayınlanmasıyla ilgili herhangi bir etik sorun bulunmamaktadır.

\section{Çıkar Çatışması}

Yazarlar herhangi bir çıkar çatışması olmadığını belirtmektedir.

\section{ORCID}

Ismail Türker (iD) https://orcid.org/0000-0003-3125-6810

Serdar Kamanlı (iD https://orcid.org/0000-0003-1936-7550

Mehmet Fatih Çelen (iD https://orcid.org/0000-0002-2513-3980

\section{Kaynaklar}

Bougon, M., Protais, J. ve Menec, M. (1986). Variation in laying performance and egg quality as a function of cage tier in the battery. Bullettin D'information Station Experimentale d'Aviculture de Ploufragen, 26(1), 17-18. https://2efa0c5cc9999d30115bf9a8d336ac32ce0c5788.vetisonline.com/cabdirect/abstract/198 
$60100415 ? q=()+$ Variation+in+laying+performance+and+egg+quality+as+a+function+of+cage+tie $\mathrm{r}+\mathrm{in}+$ the+battery)

Christmas, R. B., Harms, R. H. ve Sloan, D. R. (1996). Effect of light stimulation on pullets. Journal of Applied Poultry Research, 5,173-179. https://doi.org/10.1093/japr/5.2.173

Darre, M. J. ve Rock, J. S. (1995). Compact fluorescent lamps under commercial poultry house conditions. Journal of Applied Poultry Research, 4, 105-108. https://doi.org/10.1093/japr/4.1.105

Durmuş, I.., Karaçay, N. ve Kamanlı, S. (2004). Yumurta tavuklarında ışığın fizyolojik etkisi ve aydınlatma programları. Ziraat Mühendisliği Dergisi, 342, 28-31. https://docplayer.biz.tr/11452818-Yumurta-tavuklarinda-isigin-fizyolojik-etkisi-ve-aydinlatmaprogramlari.html

Durmuş, I. ve Kamanlı, S. (2012). Yumurtacı tavuklarda kafes katlarının bazı verim özelliklerine etkisi ile verimler arasındaki ilişkilerin belirlenmesi. Akademik Ziraat Dergisi, 1(2), 77-82. https://dergipark.org.tr/tr/download/article-file/114472

Hemsworth, P. H. ve Barnett, J. L. (1989). Relationships between fear of humans, productivity an cage position of laying hens. British Poultry Science, 30(3), 505-508. https://doi.org/10.1080/00071668908417175

Jackson, M. E. ve Waldroup, P. W. (1987). Effect of cage level (tier) on performance of white leghorn chickens. Poultry Science, 66(5), 907-909. https://doi.org/10.3382/ps.0660907

Kılıç, i. ve Şimşek, E. (2006). Bursa bölgesinde bir yumurta tavuğu kümesinin yapı içi iklimsel çevre koşullarının yumurta iç ve dış kalite özellikleri üzerine etkilerinin belirlenmesi. Uludağ Üniversitesi Ziraat Fakültesi Dergisi, 21(2), 31-38. https://dergipark.org.tr/tr/pub/ziraatuludag/issue/16750/174146

Leeson, S. ve Lewis, P. D. (2004). Changes in light intensity during the rearing period can influence egg production in domestic fowl. British Poultry Science, 45(3), 316-319. https://doi.org/10.1080/00071660410001730806

Lewis, P. D., Morris, T. R. ve Perry, G. C. (1999). Light intensity and age at first egg in pullets. Poultry Science, 78(8), 1227-1231. https://doi.org/10.1093/ps/78.8.1227

Morris, T. R. (1994). Lighting for Layers: What we know and what we need to know. World's Poultry Science Journal, 50(3), 83-287. https://agris.fao.org/agrissearch/search.do?recordID=GB19960072744

Vits, A., Weitzenburger, D., Hamann, H. ve Distl, O. (2006). Influence of different tiers in furnished cages and small group system on production traits, mortality, egg quality, bone strength claw length and keel bone deformities. Archiv fur Geflügelkunde, 70(4), 145-154. https://doi.org/10.1080/00071660500303206

Yetişir, R. ve Sarıca, M. (2004). Türkoğlu, M. ve Sarıca, M. (Ed.), Tavukçuluk bilimi yetiştirme, besleme ve hastalıklar (279-329) içinde. Bey Ofset Matbaacılık, 2. Baskı.

Yıldırım, i., Parlat, S. S., Aygün, A. ve Yetişir, R. (2008). Apartman tipi kafeste uygulanan askılı aydınlatma sisteminin kahverengi yumurtacı hibritlerin performans, yumurta kalite özellikleri ve stres düzeyine etkileri. Selçuk Üniversitesi Ziraat Fakültesi Dergisi, 22(44), 7-11. http://sjafs.selcuk.edu.tr/sjafs/article/view/288 